\title{
Research on the Application of Filling-in Interactive Teaching Method in Music Education Domain
}

\author{
Hongtao Fan \\ School of Music \\ University of Jinan \\ Jinan, China
}

\begin{abstract}
The concept of filling-in interactive teaching method is proposed by the author for the first time, but the practice of this teaching method has been applied in some literature and history classes for a long time. This paper explains this teaching method mainly from the perspectives of concept expression and example demonstration, and makes a series of brief descriptions of its promotion significance based on four aspects, namely mobilizing students' motivation to learn, cultivating students' independent exploration spirit, exercising students' ability of controlling class, cultivating students' sense of teamwork and executive capacity.
\end{abstract}

Keywords-filling-in interactive teaching method; concept expression; example demonstration; signification of promotion

\section{INTRODUCTION}

\section{A. Summary Instead of Invention}

The concept of filling-in interactive teaching method is proposed by the author for the first time, but the teaching practice about this method has been applied in some literature and history classes for a long time. The classroom teaching in traditional sense has been hard to satisfy students' demand for the knowledge of different level and different aspects with the update of contemporary teaching form and teaching philosophy. In the current teaching environment, it can be said that the appearance of any new teaching method will be a necessity and a must as the material conditions to effectively realize small-sized class teaching are not available. The appearance of filling-in interactive teaching method can be regarded as the result of teachers' long-term practice and accumulation, and the greatest strength of it in practical application lies in mobilizing students' enthusiasm, "returning" the classroom to students from teacher, and of course such "return" is not to let students take a liberal attitude towards themselves in the simple sense, but to make students realize the meaningful exploration and free expression within the framework set by the teacher. However, the concept of "filling-in interactive teaching method" is not clear and relatively imperfect due to the preliminary cognitive and simple practice of the "pre-filling-in interactive teaching" by the teachers [1], as a result, the author puts forward this concept creatively, aiming to summary the experience of senior scholars, make up deficiencies combining teaching practice to realize the mature theory of this concept, and guide the teaching practice to move forward in combination with relevant cases.

\section{B. Applicable to Local Rather than Universal}

The appearance and practice of filling-in interactive teaching method is undoubtedly of positive significance for the current teaching. But what we need to make clear is that this method is not a universal template, on the contrary, it not only has the limitations of the times, but the audiences of this method currently mainly refer to the teaching group of humanities and social sciences. This is also determined by the limitation of the teaching method itself. An important premise for the filling-in interactive teaching method is that students can extract the common view and personal views effectively through reading, understanding, constructing and other ways of thinking. It seems that the teaching difficulties of natural science cannot be resolved effectively through students' personal reading, and the personal view meeting scientific logic cannot be formed, let alone to form contention with classmates and teacher in terms of view, and even cause misunderstanding many a time, although this can bring frustrated practice and exploration.

Although the scholars work tirelessly, their attempt to construct a teaching method applicable to all disciplines in terms of "humanities" and "nature" is in vain. However, we do not deny the mutual learning between some teaching methods. When the ideal has no reality base, we can only lay our hope on the practice and effort of teachers of different disciplines, just as what we will express, namely the filling-in interactive teaching method.

\section{CONCEPT EXPRESSION OF FILLING-IN INTERACTIVE TEACHING METHOD}

The following is the figure about filling-in interactive teaching method: 


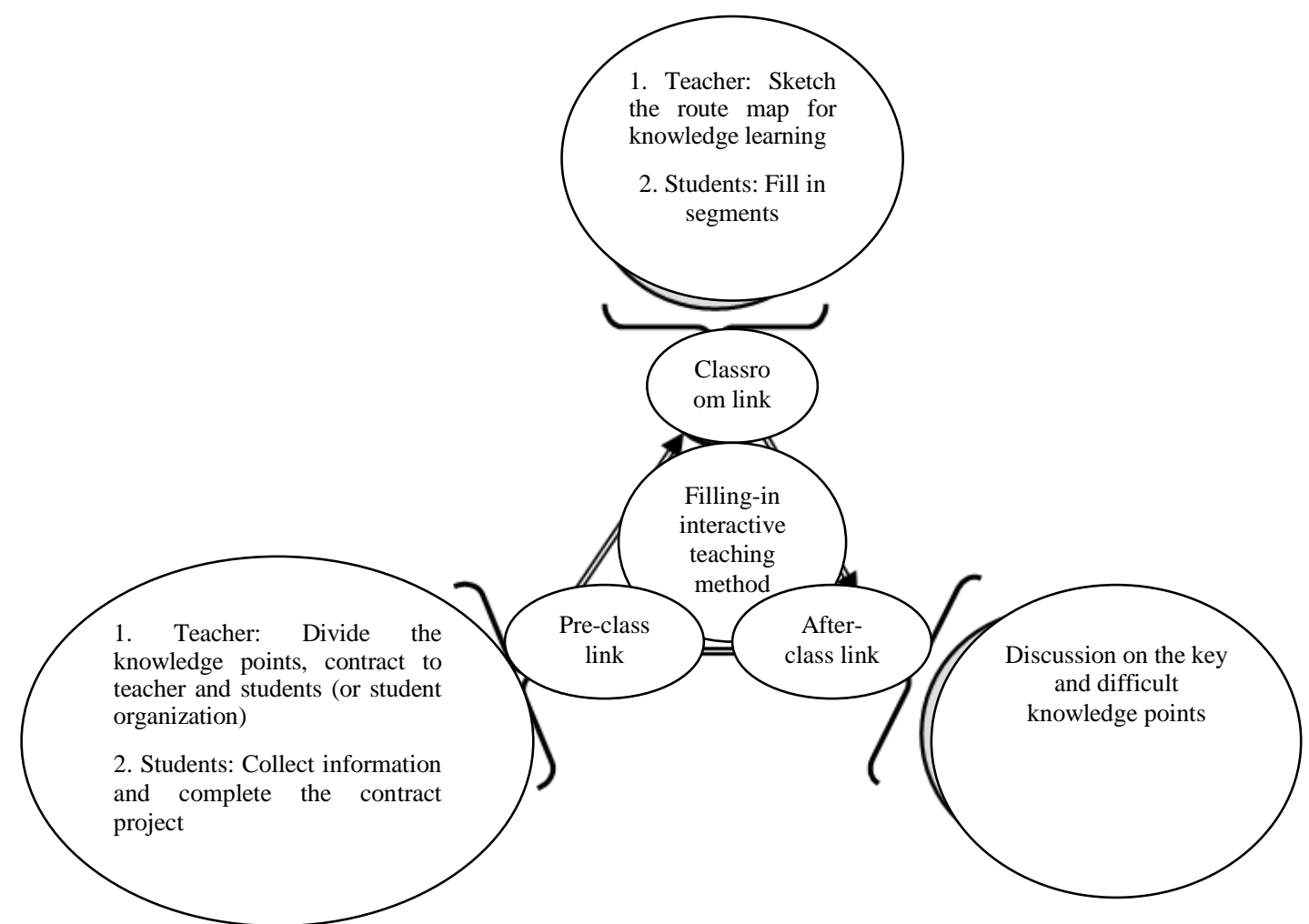

Fig. 1. The filling-in interactive teaching method.

As shown in the Figure, this teaching method mainly consists of three links, namely pre-class link, classroom link and after-class link. In fact, pre-class link overlaps after-class link in terms of time, but for the convenience of expression, they are divided as such due to different activity contents. They are expressed as below respectively.

\section{A. Press-class Link}

According to the arrangement of activity content, the more accurate title of pre-class link is "quasi-class link" (which can also be referred to as "pre-class link"). Its main content is to prepare for the classroom teaching. First of all, the teacher divides the class into different small groups according to the number of students, which is generally a group containing 5 students is the best (in order to avoid the influence on students' enthusiasm due to too many students and to prevent their lazy psychology), and select a group leader (take turns on duty within the group, and its role lies in the effective organization of group members to complete the contract task); second, teachers divides the teaching contents into different knowledge points, and contract to various groups [2](certainly, teacher can retain one key point or difficult point of the teaching content to himself / herself according to the needs of teaching); third, the group that has contracted knowledge points shall convene interim meeting lead by the group leader, and arrange the division of labor for the group members (mainly includes the data collection, PPT production, classroom presentation); fourth, pilot presentation. This link is not compulsory but it is encouraged to perform, as some problems that may reveal in the classroom can be presented with the time to resolve and relayout, on the one hand, it is beneficial to the students' language logic and expression skill, and on the other hand, it guarantees the smooth classroom order.

\section{B. Classroom Link}

Classroom link is one of the components of filling-in interactive teaching method but not the major component. In fact, one purpose of the proposal and promotion of this teaching method is to break the limitation of traditional classroom teaching, and make efforts to develop the second classroom with students' self-study as the breakthrough.

The primary task of teachers in this link is to outline the learning framework of this class briefly and clearly, list the knowledge points with logic, control the presentation time of each learning group with foresight, and stimulate students' contending about a certain point of view in a timely manner [3]. The remaining work is to organize the students to present the contracted and sorted knowledge points in the form of PPT. What should be noted here is that, the leader of learning group shall give a simple statement about the group members and the division of labor prior to the presentation, as we shall clearly know what each group member has done, but not just inspect what the speaker is doing.

\footnotetext{
2 We hope teachers can arrange the knowledge points reasonably according to the number of groups, try not to "empty" a certain group.
}

\footnotetext{
It is not advocated to carry out in class in consideration of time.
} 


\section{After-class Link}

Similarly, after-class link can also be regarded as "postclassroom link", which exists as the extension of classroom teaching in terms of time and space. In the classroom link, we have mentioned 'to stimulate students' contending about a certain view in a timely manner", but it is impossible to start a topic in depth and in detail due to the limitation of classroom time. Even though it is completed in a hurry, it is difficult to leave a profound impression in the minds of students, which leads to the failure of "contending". As a result, it is very important to set "post-classroom link". All the viewpoints presented in the classroom and those are enough to arouse students' interest and "resonance" as well as those regarded by the teacher as difficult points and key points can be discussed in the after-class link.

The significance of after-class link lies in not only learning a certain knowledge point profoundly through discussion, but also the cultivation of students' awareness of expanding second classroom. When such awareness becomes a habit gradually, the effect of classroom teaching will be enhanced greatly, and will penetrate into the learning style gradually, playing a positive role in livening up the campus culture atmosphere.

\section{Matters Which Need the Teachers to Pay Attention to During Operation}

First of all, teachers shall consider the difficulty level while splitting the knowledge points. The difficult points which will not be effective without large amount of energy and time, the viewpoints with disputes in the current academic community, and the work that just needs collecting some literal data should not be contracted to the learning group, or it will discourage their learning enthusiasm, or lead to confusion of thinking, or become lazy due to the too easy work; second, we encourage students to actively seek the advice of teacher while collecting information and extracting viewpoints, but the "nanny type" question-answer is not advocated. What we should do is to provide guidance and implicit judgment [4], and the workload of teachers here is very heavy; third, the group that has contracted tasks shall get effective division of labor internally and retain independent work space. Of course, it shall be retained compulsorily sometimes, so as to avoid after effect brought by excessive dependence.

In addition to reasonable arrangement of time and effective guidance, there are another two points need to be noted in the classroom link. First, the learning framework established by the teacher for this class shall be within the acceptable range of students' thinking. In other works, the learning route map shall be described briefly and clearly from the perspective of students' thinking. The overly obscure logic will stop students from exploring the learning points, without forming the all-dimensional knowledge

Implicit judgment refers to that while answering students' judgment about right or wrong viewpoint, the teacher does not only rely on the expression of "right" or "wrong", but through making implications, case transplantation and other ways, so as students can obtain right judgment in their own thinking. structure; second, teacher shall set strict requirements for the speaker' posture and language, as the speaker stands on the stage as a "teacher", which requires his behavior to meet the professional requirements, although it is temporary. It is true that the classroom link may encounter various problems even the emergencies, which requires the teacher to perform sufficient preparation in terms of presentation cohesion, enlightenment ideas and maintaining the teaching order, and sometimes it even needs to prepare the second scheme.

The biggest problem encountered in the after-class discussion link is research without discussion, or nonresearch, non-discussion. The signs of this problem mainly reflect in the following points: 1) the teacher does not extract students' interest accurately; 2) the argument extracted by the teacher is in the blind spot of students' knowledge structure; 3 ) the viewpoint extracted by the teacher is too obscure, and is beyond students' understanding scope; 4) students do not get into their own role. Of course, here we mainly discuss the first three points having direct relationship with teachers. For example, with respect to the resolution of the above three points in classroom link, teachers are required to observe carefully, keep a good record, have a keen awareness of students' reaction toward some knowledge points. When such positive reaction is projected in the seminar, it is bound to get the resonance and contending.

\section{SignifICANCE OF PROMOTING THE FILLING-IN INTERACTIVE TEACHING METHOD}

The significance of filling-in interactive teaching method not only lies in its contribution to the birth of certain teaching model in terms of theory, more importantly, it lies in the provision of excellent display and exercise platform in terms of mobilizing students' learning enthusiasm, training students' independent exploration spirit, exercising students' ability of controlling the class, and cultivation of students' teamwork awareness and executive ability.

\section{A. Mobilize Students' Learning Enthusiasm}

The teaching method in traditional sense neglects the attention to students' active learning because of simply focusing on teaching, which makes the knowledge learned from book shallow. Students need the knowledge to cope with the exam, and they will forget the knowledge after the exam. The primary significance of filling-in interactive teaching method lies in mobilizing students' learning initiative; of course such mobilization is realized under the teacher's guidance with logic and purpose. Teachers divide the knowledge into several points according to teaching contents, and contract to student groups; students will complete the contracted project through collection of data and purification of viewpoints. As each student will get his own task and shall complete the task within specified time, which greatly mobilizes students' initiative. It seems that such mobilization has strong passiveness on the surface, but from students' psychological perspective, it is a kind of affirmation of self-competence, and a way for individual realization, as a result, the passiveness is diluted to active participation. 


\section{B. Cultivate Students' Independent Exploratory Spirit}

In the pre-class link, the division of group and contracting of knowledge points require every student to tackle his own subproject. Such responsibility requires each participant to study independently and assemble together organically, which a kind of test and exercise of individual study ability. Students have the independent spirit more of less, but the ability to study independently is to be cultivated gradually. The purpose of independent study is reached undoubtedly through the practice of above links.

\section{Exercise Students' Ability of Controlling the Class}

In the link of classroom presentation, group members shall analysis and make statement about the contracted knowledge points on the platform, which is the embellishment in the previous teaching links. However, with the promotion and practice of filling-in interactive teaching method, such presentation becomes a conventional form. In addition, the non-fixed group members at each presentation will expand the probability of students' participating in teaching. The improvement of class control ability has exercised students' language organization and expression ability on the other hand. The fluent and logic expression is always the important consideration item for success no matter what job the student will engage in

\section{Cultivate Students' Teamwork Awareness and Executive Ability}

Students' teamwork awareness and executive ability is a process of cultivation, which is difficult to popularize and exercise simply relying on student association due to insufficient participation, while the project contract of filling-in interactive teaching method can make up the defect of cultivation. Group leader convenes the group meeting according to contracted knowledge points, to discuss the refinement of knowledge points, division of labor for the group members; in the classroom presentation, a statement will be made regarding the research result as overall crystallization; group leader monitors the member's schedule within specified time and so on. All these have played an important role in students' teamwork awareness formation and the development of their executive ability.

\section{CONCLUSION}

The purpose of theoretical expression of filling-in interactive teaching method is to make more people understand such teaching method. The example demonstration of such teaching method is to explain the application of this teaching method, which has been recognized by the teaching practitioners, and to make exchanges with experts from all walks of life through this paper, hoping to make progress. At the beginning of the birth of this teaching method, our theoretical research is more about encouragement and advocacy. However, with the change of teaching environment and the accumulation of teaching practice, the filling-in interactive teaching method needs to correct its own defects. Only in this way can it actively serve the teaching practice.

\section{REFERENCES}

[1] Liu Xianjun. Innovative Education Concept Promotes the Talent Cultivation Mode Reform [J]. China Higher Education. 2009(01)

[2] Xin Jixiang. Cultural Conflicts in Course and Teaching Reform [J]. Education Review. 2008(04)

[3] Chen Haichao. How Teachers Recognize and Adjust Their Own Role in Teaching Reform [J]. Journal of Hunan First Normal University. 2008(02)

[4] Xiong Huajun. Meaning Generation---New Value Orientation of in Contemporary College Teaching [D]. Huazhong University of Science and Technology. 2008

[5] Fang Mingjun. Implicit Incentive Theory for University Teachers [D]. Huazhong University of Science and Technology. 2008

[6] Zhu Weihong. College Cultural Innovation and Organization Development [D]. Huazhong University of Science and Technology. 2008

[7] Liu Xiaoqiang. Discipline Construction---Meta-perspective Investigation [D]. Xiamen University. 2008

[8] Tian Huwei. Current Situation, Problems and Methods of Research Methods of Higher Education in China [D]. Huazhong University of Science and Technology. 2007

[9] Wang Ling. On the Relationship between Transformation of American Knowledge View and Undergraduate Teaching Mode Reform [D]. Northeast Normal University. 2007

[10] Li Xiaoyang. Teacher's Experience and Its Generation [D]. Huazhong University of Science and Technology. 2009

[11] Mao Jinghuan. Generation of Equal Experience and Class Teaching Community [D]. Nanjing Normal University. 2004

[12] Sun Yaling. Research on Standards of Classroom Teaching Effectiveness[D]. East China Normal University. 2004. 